\title{
Media Digitalisasi Pembelajaran Jarak Jauh Menggunakan Model Blended Learning di Era Pandemi COVID 19
}

\author{
Sri Rejeki ${ }^{1}$, Dwi Budi Srisulistiowati ${ }^{1, *}$ \\ ${ }^{1}$ Fakultas IImu Komputer; Universitas Bhayangkara Jakarta Raya, Jl.Perjuangan No.81, \\ Marga Mulya, Kec.Bekasi Utara, Kota Bekasi, Jawa Barat 17143; e-mail: \\ sri.rejeki@dsn.ubharajaya.ac.id dwibudi@dsn.ubharajaya.ac.id \\ * Korespondensi: e-mail: dwibudi@dsn.ubharajaya.ac.id \\ Submitted: 17/12/2021; Revised: 20/12/2021; Accepted: 28/12/2021; Published: 31/12/2021
}

\begin{abstract}
Electronic learning (E-learning) is essentially an educational learning medium through the use of computer or internet technology, namely web-based learning technology (Web Based Instuc- tion). the implementation of e-learning is one part of alternative technology in helping to run the learning curriculum during the Covid 19 pandemic. aimed at knowing the process of implement- ing Blended Learning learning with google classroom XI-TKJ material class, to find out the per-ceptions of teachers and students towards the implementation of the COVID19 pandemic era google classroom learning. This research uses a qualitative method approach, the data sources in this study include primary and secondary data sources. Data collection techniques using the method of observation, interviews, and documentation. Checking the validity of the data using credibil - ity, transferbility, dependability, and confirmability.
\end{abstract}

Keywords: Blended Learning, Covid 19, Elearning, Google Classroom, Pandemic

\section{Abstrak}

Pembelajaran elektronik (e-learning) sebenarnya merupakan sarana pembelajaran pendidikan melalui pemanfaatan teknologi komputer atau internet, yaitu teknologi pembelajaran berbasis web (web-based instruction). Adanya implementasi e-learning menjadi salah satu bagian teknologi alternatif dalam membantu berjalannya kurikulum pembelajaran secara during di masa pandemi covid 19. Penelitian ini dijalankan guna mengetahui proses pelaksanaan pembe- lajaran Blended Learning dengan menggunakan google classroom materi kelas XITKJ, untuk mencari tahu persepsi guru maupun siswa terhadap dilaksanaannya pembelajaran google classroom saat terjadinya pandemi COVID-19. Penelitian ini memakai metode pendekatan yaitu kualitatif, dengan sumber data yang ada dalam penelitian ini meliputi sumber data primer dan sekunder. Teknik pengumpulan data menggunakan metode observasi (pengamatan), wawan- cara (bertanya), serta dokumentasi. Pengecekan keabsahan data dengan credibility (keterpercayaan), transferbility (keteralihan), dependanility (ketergantungan), dan confirmability (kepastian).

Kata kunci: Blended Learning , Covid 19, Elearning, Google Classroom, Pandemic

\section{Pendahuluan}

Pembelajaran elektronik (e-learning) sebenarnya merupakan sarana pembelajaran pendidikan melalui pemanfaatan teknologi komputer atau internet, yaitu teknologi pembelajaran berbasis web (web-based instruction). Adanya implementasi e-learning menjadi salah satu bagian teknologi alternatif dalam membantu berjalannya kurikulum pembelajaran secara daring 
di masa pandemi covid 19. Di SMK Yadika Tanggerang proses pembelajaran masih secara online dalam kondisi pandemi covid 19. Apalagi wabah covid 19 sampai saat ini masih belum bisa teratasi. Sehingga, masih rawan untuk terkena wabah yang akhirnya diputuskan oleh pemerintah untuk seluruh kegiatan belajar serta mengajar masih harus berjalan diadakan secara daring. Maka dari itu, adanya implementasi e-learning dalam memanfaatkan google classroom menjadi salah satu bagian teknologi alternatif dalam kurikulum pembelajaran secara daring. Observasi ini bertujuan untuk mengimplementasikan elearning kurikulum pembelajaran di SMK Yadika Tanggerang, Subjek pada penelitian ini adalah beberapa siswa didik kelas XITKJ di sekolah tersebut.

Sistem pembelajaran campuran (Blended Learning) menggabungkan instruksi tatap muka serta instruksi lain yang dimediasi menggunakan perangkat computer (Hrastinski, 2019).

Electronic learning (E-learning) pada hakikatnya adalah sebagai media pembelajaran pendidikan melalui penggunaan teknologi komputer atau internet. (Udin Syaefudin Sa'ud, 2010).

E-learning ialah sistem pendidikan yang memanfaatkan kemajuan teknologi, berbentuk aplikasi elektronik guna membantu pengembangan kegiatan belajar mengajar dengan menggunakan internet, intranet atau media komputer yang lain sebagai media pembelajarannya, maka pembelajaran daring bisa terjadi proses pembelajaran tanpa harus secara langsung bertatap muka serta pengembangan ilmu pengetahuan kepada para pelajar dan mahasiswa dapat berlangsung dengan baik (Tersegno \& Berlin, 2003).

Teknologi Informasi dan Komunikasi atau biasa disebut dengan istilah sebagai berikut: information, communication, and teknologi (ICT) mendorong para pembuat keputusan untuk mencantumkan muatan TIK ke dalam kurikulum (Isnaini et al., 2015).

Aplikasi google classroom mempunyai fitur sebagai pendukung dalam proses pembelajaran e-learning dan dapat digunakan oleh guru saat proses pembelajaran (Iskandar, 2020).

Kejadian yang terjadi saat ini membuat dunia Pendidikan berubah sejak adanya dampak pandemic COVID-19, sehingga pemerintah untuk sementara waktu meliburkan lembaga pendidikan. Selain itu pemerintah juga membatasi kegiatan manusia terutama dalam kegiatan luar rumah sebagai cara membatasi interaksi antar banyak orang sehingga tujuan untuk memutus penyebaran COVID-19. Kebijakan tersebut tidak hanya berlaku di Indonesia saja, tetapi juga di negara-negara yang telah terkena dampak COVID-19.

Adanya kearifan ini maka dunia pendidikan melaksanakan pembelajaran dengan baik meskipun harus dari jarak yang jauh atau bisa disebut pembelajaran daring (dalam jaringan). Pelaksanaan daring atau pembelajaran dalam jaringan di era pandemic COVID-19 ini pengajar diharuskan untuk menggunakan serta memilih metode apa yang tepat agar aktivitas dalam pembelajaran tetap berlangsung sehingga terciptalah interaksi yang edukatif. 


\section{Metode Penelitian}

Metode penelitian adalah proses di mana penyelidikan dilakukan (Sunyoto, 2016). Menguraikan observasi secara berurutan, termasuk rancangan observasi, kegiatan observasi (dalam bentuk langkah - langkah, struktur kode dan lain sebagainya), bagaimana untuk uji coba dan perolehan data. Penjelasan dari proses observasi didukung daftar pustaka, dalam menjelaskan secara ilmiah (Herlawati, Handayanto, R. T., 2018).

Penelitian ini dilakukan pada bulan maret - mei 2021 karena pelaksanaan penelitiannya ini di tengah kondisi pandemi COVID19, pelaksanaan penelitian dilakukan dengan komunikasi secara during yaitu menggunakan media whatsapp, aplikasi google meet untuk berdiskusi dan tanya jawab serta untuk komunikasi bahan informasi dalam proses daring menggunakan google classroom.

Penelitian ini menggunakan pendekatan secara kualitatif, observasi ini juga meliputi penggunaan sumber data primer dan sekunder.

Analisis SWOT adalah metode perencanaan strategis digunakan untuk menilai kekuatan, kelemahan, peluang dan ancaman (threats) dalam proyek atau spekulasi komersial. Empat faktor ini Ini merupakan akronim SWOT (Strengths, Weaknesses, Opportunities and Threats). Perencanaan strategi pemasaran dan analisis SWOT. Proses ini melibatkan penentuan tujuan spesifik dari bisnis atau spekulasi proyek dan identifikasi faktor internal dan eksternal yang mendukung dan tidak mendukung (Suryatman et al., 2021).

Tabel 1. Analisa SWOT SMK Yadika 2

\begin{tabular}{|c|c|}
\hline Kekuatan (Strenght) & Kelemahan (Weakness) \\
\hline $\begin{array}{l}\text { SMA Yadika } 2 \text { Tangerang memiliki sarana } \\
\text { dan prasarana yang baik; } \\
\text { Memiliki tenaga pendidik yang } \\
\text { berwawasan luas dan ahli dalam } \\
\text { Bidangnya }\end{array}$ & $\begin{array}{l}\text { Sistim penilaian masih menggunakan } \\
\text { kertas yang cukup memakan waktu } \\
\text { dalam menginpit. }\end{array}$ \\
\hline Peluang ( Opportunities) & Ancaman (Threat) \\
\hline $\begin{array}{l}\text { Banyaknya perkembangan teknologi Informasi } \\
\text { yang dapat di akses dengan mudah; } \\
\text { Tombulnya kepercayaan dari orang tua murid } \\
\text { dalam memenatau hasil belajar siswa }\end{array}$ & $\begin{array}{l}\text { Hilangnya data nilai siswa jika terjadi } \\
\text { kerusakan pada media peny- impanan } \\
\text { data. }\end{array}$ \\
\hline
\end{tabular}

Pada Tabel 1 menjelaskan tentang Analisa SWOT SMK Yadika 2 dilihat dari kekuatan, kelemahan, peluang dan ancaman. Analisis data adalah supaya yang dilaksanakan dengan jalan melakukan kerja dengan data, observasi data, memilihnya menjadi satu sehingga bisa dijalankan, mensintetiskannya, memeriksa dan sesuai gambaran, sesuai kebutuhan dan kepentingan sesuai orang lain. (Lexy J. Moleong, 2013). Analisis data di observasi ini menggunakan kajian bagan alur "Miles dan Huberman" (Sugiyono., 2016).

\section{Hasil dan Pembahasan}

Matriks SWOT adalah metode sistematis untuk mengidentifikasi empat faktor utama Sertakan dalam analisis yang menggambarkan kecocokan terbaik di dalam. Analisis ini didasarkan pada asumsi bahwa strategi akan Memaksimalkan keuntungan dan peluang, 
meminimalkan kerugian dan ancaman. Matriks SWOT digunakan untuk mengembangkan empat jenis alternatif : Strategi yaitu strategi SO (Strength-Opportunity), WO (WeaknessOpportunity) Peluang), strategi ST (Kekuatan-Ancaman) dan Strategi WT (Kekuranganancaman).

Tabel 2. Analisa SWOT Blended Learning

\begin{tabular}{|c|c|c|c|}
\hline STRENGTH (S) & WEAKNESS (W) & OPPORTUNITIES (O) & THREATS (T) \\
\hline $\begin{array}{l}\text { 1. Sangat mobile } \\
\text { friendly untuk pemula }\end{array}$ & $\begin{array}{l}\text { 1. Sulit dalam } \\
\text { melakukan penilaian } \\
\text { di versi Mobile }\end{array}$ & $\begin{array}{lr}1 . & \text { Perkembangan } \\
\text { Teknologi } & \text { yang } \\
\text { semakin pesat } & \end{array}$ & $\begin{array}{l}\text { 1. Cuaca yang } \\
\text { ekstrem } \\
\text { menghambat } \\
\text { pembelajaran }\end{array}$ \\
\hline $\begin{array}{l}\text { 2. Mudah mengelola } \\
\text { tugas yang diberikan }\end{array}$ & $\begin{array}{l}\text { 2. Saat Google Drive } \\
\text { Penuh file tidak bisa } \\
\text { dikirim }\end{array}$ & $\begin{array}{l}\text { 2. Bebas dari iklan dan } \\
\text { aman }\end{array}$ & $\begin{array}{l}\text { 2. Sangat mudah } \\
\text { untuk melihat } \\
\text { pengumuman dari } \\
\text { pengajar }\end{array}$ \\
\hline $\begin{array}{l}\text { 3. Semua file masuk } \\
\text { ke Google Drive kita }\end{array}$ & & $\begin{array}{l}\text { 3. Tersedia secara } \\
\text { gratis } 100 \%\end{array}$ & $\begin{array}{l}\text { 3. Penggunaannya } \\
\text { masih tergantung } \\
\text { kepada kestabilan } \\
\text { internet }\end{array}$ \\
\hline $\begin{array}{l}4 . \quad \text { Mengurangi } \\
\text { penggunaan kertas }\end{array}$ & & $\begin{array}{l}\text { 4. Waktu Pengiriman } \\
\text { masih bisa diatur } \\
\text { dengan cara } \\
\text { mengundurkan waktu }\end{array}$ & 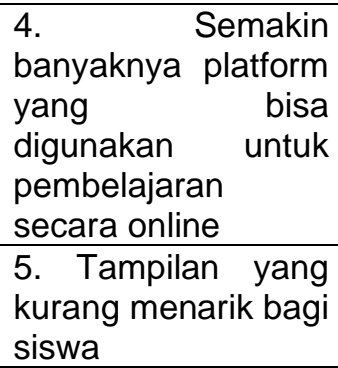 \\
\hline
\end{tabular}

Pada Tabel 2 menjelaskan tentang Analisa SWOT elearning yang ada di SMK Yadika 2 dilihat dari Strength, weakness, Opportunities, Threats. Berikut ini merupakan hasil perhitungan skala likert dengan melibatkan sampel 30 orang siswa dan 10 pertanyaan yang diberikan mengenai dilaksanakannya blended learning.

\subsection{Sampel Data Siswa}

Data siswa yang dipilih merupakan sampel dengan banyak data 30 orang siswa. Pada Tabel 3 menjelaskan tentang sampel data siswa kelas XI TKJ yang berjumlah 30 siswa.

Tabel 3. Sampel Data Siswa Kelas XI TKJ

\begin{tabular}{clcc}
\hline No & \multicolumn{1}{c}{ Nama Siswa } & Jenis Kelamin & Kelas \\
\hline 1. & Ahmad Jaelani & Laki & XI-TKJ A \\
\hline 2. & Aji Suryana & Laki & XI-TKJ A \\
\hline 3. & Atika Suri Utami & Perempuan & XI-TKJ A \\
\hline 4. & Ayu Nur Syafitri & Perempuan & XI-TKJ B \\
\hline 5. & Bernadetta & Perempuan & XI-TKJ B \\
\hline 6. & Bisma Alamsyah & Laki & XI-TKJ B \\
\hline 7. & Dodi Iskandar & Laki & XI-TKJ B \\
\hline 8. & Dicky Firmansyah & Laki & XI-TKJ A \\
\hline 9. & Dennis Roberto Michael & Laki & XI-TKJ A \\
\hline 10. & Edo Febriansyah & Laki & XI-TKJ A \\
\hline 11. & Ernita Ayu Lutfhia & Perempuan & Xl-TKJ B \\
\hline 12. & Erni Khoirunnisa & Perempuan & XI-TKJ B \\
\hline 13. & Friska Emmanuela & Perempuan & XI-TKJ A
\end{tabular}




\begin{tabular}{clcc}
\hline No & \multicolumn{1}{c}{ Nama Siswa } & Jenis Kelamin & Kelas \\
\hline 14. & Fadhilah & Laki & XI-TKJ B \\
\hline 15. & Fitrul Dwi Rustapa & Laki & XI-TKJ A \\
\hline 16. & Hilman Syah & Laki & XI-TKJ B \\
\hline 17. & Hendro Siswanto & Laki & XI-TKJ A \\
\hline 18. & Hamka Nur Hamzah & Laki & XI-TKJ A \\
\hline 19. & Haris Harun & Laki & XI-TKJ B \\
\hline 20. & Immanuel Sitohang & Laki & XI-TKJ B \\
\hline 21. & Indra Kahfi & Laki & XI-TKJ A \\
\hline 22. & Muhammad Nasir & Laki & XI-TKJ A \\
\hline 23. & Mentari Noor Syafitri & Perempuan & XI-TKJ B \\
\hline 24. & Melva Lutfhi & Perempuan & XI-TKJ A \\
\hline 25. & Nisya Al Mufid & Laki & XI-TKJ A \\
\hline 26. & Oscar Leonardo Rumbay & Laki & XI-TKJ A \\
\hline 27. & Puji Rahayu Rahmawati & Perempuan & XI-TKJ B \\
\hline 28. & Riskya & Perempuan & XI-TKJ B \\
\hline 29. & Sumayyah Hassan & Perempuan & Xl-TKJ B \\
\hline 30. & Vivi Indrawati & Perempuan & XI-TKJ A \\
\hline
\end{tabular}

Sumber: Hasil Penelitian (2021)

\subsection{Perhitungan Skala Likert}

Setelah sampel data siswa didapatkan, langkah selanjutnya adalah mem- berikan pertanyaan kepada masing-masing siswa mengenai tanggapan mereka dengan diberlakukannya blended learning. Bobot atau skor yang diberikan dalam pertanyaan ini adalah $:(\mathrm{SS})=$ Sangat Setuju $=5$ Point, $(\mathrm{S})=$ Setuju $=4$ Point, $(\mathrm{R})=$ Ragu-Ragu $=3$ Point, $(\mathrm{TS})=$ Tidak Setuju $=2$ Point dan (STS) $=$ Sangat Tidak Setuju $=1$ Point.

Tabel 4. Pertanyaan Mengenai Pemanfaatan Blended Learning

\begin{tabular}{|c|c|c|c|c|c|c|}
\hline \multirow[t]{2}{*}{ No } & \multirow[t]{2}{*}{ Pertanyaan } & \multicolumn{5}{|c|}{ Jawaban (Jumlah Responden) } \\
\hline & & SS & S & $\mathrm{R}$ & TS & STS \\
\hline 1 & $\begin{array}{l}\text { Apakah aplikasi google classroom } \\
\text { mudah digunakan? }\end{array}$ & 16 & 6 & 2 & 4 & 2 \\
\hline 2 & $\begin{array}{l}\text { Apakah penerapan metode blendedlearning di sekolah } \\
\text { anda berjalan } \\
\text { dengan baik? }\end{array}$ & 12 & 8 & 5 & 1 & 4 \\
\hline 3 & $\begin{array}{l}\text { Apakah dengan } \\
\text { blended learning } \\
\text { semangat belajar? }\end{array}$ & 10 & 11 & 5 & 1 & 3 \\
\hline 4 & $\begin{array}{l}\text { Apakah kegiatan belajar mengajar dengan metode } \\
\text { blender learninglebih mudah dipahami siswa dari pada } \\
\text { pembelajaran saat bertatap } \\
\text { muka? }\end{array}$ & 7 & 3 & 10 & 8 & 2 \\
\hline 5 & $\begin{array}{l}\text { Apakah kegiatan belajar mengajar saat bertatap muka } \\
\text { lebih mudah dipahami siswa dari pada } \\
\text { pembelajaran blended learning? }\end{array}$ & 15 & 2 & 3 & 4 & 6 \\
\hline 6 & $\begin{array}{l}\text { Setujukah anda jika blended learning nantinya dijadikan } \\
\text { metode utama dalam kegiatan belajar } \\
\text { mengajar? }\end{array}$ & 12 & 7 & 5 & 3 & 3 \\
\hline 7 & $\begin{array}{l}\text { Apakah guru di sekolah anda dapat memaksimalkan } \\
\text { aplikasi }\end{array}$ & 20 & 5 & 0 & 3 & 2 \\
\hline 8 & $\begin{array}{l}\text { Apakah internet menjadi kendala utama anda dalam } \\
\text { menjalani pembelajaran jarak jauh? }\end{array}$ & 8 & 5 & 7 & 5 & 5 \\
\hline
\end{tabular}




\begin{tabular}{|c|c|c|c|c|c|c|}
\hline \multirow[t]{2}{*}{ No } & \multirow[t]{2}{*}{ Pertanyaan } & \multicolumn{5}{|c|}{ Jawaban (Jumlah Responden) } \\
\hline & & SS & S & $\mathrm{R}$ & TS & STS \\
\hline 9 & $\begin{array}{l}\text { Apakah masih ada guru yang tidak } \\
\text { bisa memanfaatkan blended learning atau aplikasi } \\
\text { google classroom sebagai media pembelajaran dengan } \\
\text { baik? }\end{array}$ & 0 & 0 & 5 & 15 & 10 \\
\hline 10 & $\begin{array}{l}\text { Apakah dengan } \quad \text { adanya pemanfaatan } \\
\text { blended learning ini membuat minat belajar anda } \\
\text { menurun? }\end{array}$ & 2 & 4 & 4 & 13 & 7 \\
\hline
\end{tabular}

Tabel 4. Menjelaskan tentang 10 pertanyaan mengenai Blended Learning yang diberikan ke 30 siswa. Di kelas XITKJ.

Setelah data jawaban dari responden diterima, selanjutnya data tersebut akan dihitung dengan rumus $\mathbf{T}$ x Pn, dimana T merupakan jumlah responden yang memilih, dan Pn adalah angka skor likert., Selanjutnya melakukan perhitungan indeks dengan rumus :

Indeks $(\%)=($ Total Skor $/$ Skor Maksimum) x 100\%

Untuk mencari nilai skor maksimum digunakan rumus sebagai berikut Skor maksimum (Jumlah Responden $x$ Skor Tertinggi Likert) = 30x5 = 150. Berdasarkan rumus di atas maka dapat kita tentukan nilai skor maksimum adalah 150. Hasil perhitungan indeks nantinya akan dicocokan dengan nilai interval penilaian sebagai berikut Angka 0\% - 19,99\%= Sangat Tidak Setuju; Angka 20\% - 39,99\% = Tidak Setuju; Angka 40\% - 59,99\% = Ragu-ragu; Angka 60\% - 79,99\% = Setuju; Angka 80\% - 100\% = Sangat Setuju.

1. Perhitungan Skala Likert Pertanyaan Nomor 1

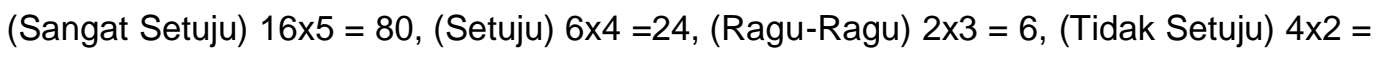

8 , (Sangat Tidak Setuju) $2 \times 1=2$, sehingga total skor adalah $80+24+6+8+2=120$ Indeks $(\%)=(120 / 150) \times 100 \%=80 \%$

Karena nilai indeks yang didapatkan adalah 80\% maka dapat disimpulkan bahwa responden "SANGAT SETUJU"

\section{Perhitungan Skala Likert Pertanyaan Nomor 2}

(Sangat Setuju) $12 \times 5=60$, (Setuju) $8 \times 4=32$, (Ragu-Ragu) $5 \times 3=15$, (Tidak Setuju) $1 \times 2$ $=2$, (Sangat Tidak Setuju) $4 \times 1=4$, sehingga total skor adalah $60+32+15+2+4=113$ Indeks $(\%)=(113 / 150) \times 100 \%=75 \%$

Karena nilai indeks yang didapatkan adalah 75\% maka dapat disimpulkan bahwa responden "SETUJU"

\section{Perhitungan Skala Likert Pertanyaan Nomor 3}

(Sangat Setuju) $10 \times 5=50$, (Setuju) $11 \times 4=44$, (Ragu-Ragu) $5 \times 3=15$, (Tidak Setuju) $1 \times 2=2$, (Sangat Tidak Setuju) $3 \times 1=3$, sehingga total skor adalah $50+44+15+2+3=114$ Indeks $(\%)=(114 / 150) \times 100 \%=76 \%$

Karena nilai indeks yang didapatkan adalah 76\% maka dapat disimpulkan bahwa responden "SETUJU"

\section{Perhitungan Skala Likert Pertanyaan Nomor 4}

(Sangat Setuju) $7 \times 5=35$, (Setuju) $3 \times 4=12$, (Ragu-Ragu) 10x3 = 30, (Tidak Setuju) $8 \times 2$ 
$=16$, (Sangat Tidak Setuju) $2 \times 1=2$, sehingga total skor adalah $35+12+30+16+2=95$ Indeks $(\%)=(95 / 150) \times 100 \%=63 \%$

Karena nilai indeks yang didapatkan adalah $63 \%$ maka dapat disimpulkan bahwa responden "SETUJU"

\section{Perhitungan Skala Likert Pertanyaan Nomor 5}

(Sangat Setuju) $15 \times 5=75$, (Setuju) $2 \times 4=8$, (Ragu-Ragu) $3 \times 3=9$, (Tidak Setuju) $4 \times 2=$ 8 , (Sangat Tidak Setuju) $6 \times 1=6$, sehingga total skor adalah $75+8+9+8+6=106$ Indeks $(\%)=(106 / 150) \times 100 \%=70 \%$

Karena nilai indeks yang didapatkan adalah $70 \%$ maka dapat disimpulkan bahwa responden "SETUJU"

\section{Perhitungan Skala Likert Pertanyaan Nomor 6}

(Sangat Setuju) $12 \times 5=60$, (Setuju) $7 \times 4=28$, (Ragu-Ragu) $5 \times 3=15$, (Tidak Setuju) $3 \times 2$ $=6$, (Sangat Tidak Setuju) $3 \times 1=3$, sehingga total skor adalah $60+28+15+6+3=112$ Indeks $(\%)=(112 / 150) \times 100 \%=74 \%$

Karena nilai indeks yang didapatkan adalah $74 \%$ maka dapat disimpulkan bahwa responden "SETUJU"

\section{Perhitungan Skala Likert Pertanyaan Nomor 7}

(Sangat Setuju) $20 \times 5=100$, (Setuju) $5 \times 4=20$, (Ragu-Ragu) $0 \times 3=0$, (Tidak Setuju) $3 \times 2$ $=6$, (Sangat Tidak Setuju) $2 \times 1=2$, sehingga total skor adalah $100+20+0+6+2=128$ Indeks $(\%)=(128 / 150) \times 100 \%=85 \%$

Karena nilai indeks yang didapatkan adalah $85 \%$ maka dapat disimpulkan bahwa responden "SANGAT SETUJU"

\section{Perhitungan Skala Likert Pertanyaan Nomor 8}

(Sangat Setuju) $8 \times 5=40$, (Setuju) $5 \times 4=20$, (Ragu-Ragu) $7 \times 3=21$, (Tidak Setuju) $5 \times 2=$ 10, (Sangat Tidak Setuju) $5 \times 1=5$, sehingga total skor adalah $40+20+21+10+5=96$ Indeks $(\%)=(96 / 150) \times 100 \%=64 \%$

Karena nilai indeks yang didapatkan adalah $64 \%$ maka dapat disimpulkan bahwa responden "SETUJU"

\section{Perhitungan Skala Likert Pertanyaan Nomor 9}

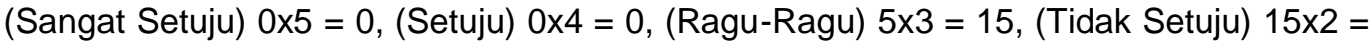
30, (Sangat Tidak Setuju) $10 \times 1=10$, sehingga total skor adalah $0+0+15+30+10=55$ Indeks $(\%)=(55 / 150) \times 100 \%=36 \%$

Karena nilai indeks yang didapatkan adalah $36 \%$ maka dapat disimpulkan bahwa responden "TIDAK SETUJU"

\section{Perhitungan Skala Likert Pertanyaan Nomor $\mathbf{1 0}$}

(Sangat Setuju) $2 \times 5=15$, (Setuju) $4 \times 4=16$, (Ragu-Ragu) $4 \times 3=12$, (Tidak Setuju) $13 \times 2$ $=26$, (Sangat Tidak Setuju) $7 \times 1=7$, sehingga total skor adalah $15+16+12+26+7=76$ Indeks $(\%)=(76 / 150) \times 100 \%=50 \%$ 
Karena nilai indeks yang didapatkan adalah 50\% maka dapat disimpulkan bahwa responden "RAGU - RAGU"

\section{Kesimpulan}

Hasil evaluasi proses pembelajaran dengan menggunakan blended learning sudah cukup terpenuhi, ini dapat dilihat dari hasil perhitungan skala likert yang rata - rata diatas $70 \%$. Faktor pendukung: motivasi siswa, bimbingan orang tua dan akses internet dan jaringan merupakan faktor utama pembelajaran dapat berjalan dengan baik.

\section{Daftar Pustaka}

Herlawati, Handayanto, R. T., \& S. (2018). Neural network regression with support vector regression for land-use growth prediction. Proceedings of the 3rd International Conference on Informatics and Computing.

Hrastinski, S. (2019). What Do We Mean by Blended Learning? TechTrends, 63(5), 564-569. https://doi.org/10.1007/s11528-019-00375-5

Iskandar, D. (2020). No TitleAplikasi Pembelajaran Berbasis TIK. Yayasan Kita Menulis.

Isnaini, M., Kusuma, D., \& Noviani, L. (2015). Pengaruh Kompetensi Dosen Dan Fasilitas Belajar Terhadap Kepuasan Mahasiswa Pendidikan Ekonomi Fkip Uns. BISE: Jurnal Pendidikan Bisnis Dan Ekonomi, 1(2), 1-20. https://jurnal.uns.ac.id/bise/article/view/17968

Lexy J. Moleong, D. M. A. (2013). Metodologi Penelitian Kualitatif. ROSDA.

Sugiyono. (2016). Metode Penelitian Kuantitatif, Kualitatif, dan R\&D. Alfabeta. http://scholar.google.com/scholar?cluster=10328650190657588078\&hl=en\&oi=scholarr Sunyoto, D. (2016). Metodologi Penelitian Akuntansi. REFIKA.

Suryatman, T. H., Kosim, M. E., \& S, G. E. (2021). Perencanaan Strategi Pemasaran Dengan Analisis Swot Dalam Upaya Meningkatkan Penjualan Sepatu Adidas Di PT . Panarub Industry Marketing Strategy Planning With Analysis Swot In Effort To Increase Sales Of Adidas Shoe At PT . Panarub Industry. Journal Industrial Manufacturing, 6(1), 43-56. http://jurnal.umt.ac.id/index.php/jim/article/view/4117/2355

Tersegno, M. M., \& Berlin, L. (2003). Biopsy or Follow-Up Mammography? [2] (multiple letters). American Journal of Roentgenology, 181(6), 1716-1717. https://doi.org/10.2214/ajr.181.6.1811716b

Udin Syaefudin Sa'ud. (2010). Inovasi Pendidikan. Alfabeta. 